\title{
Functional Values of the English Clause in Grammatical Analysis
}

\author{
Raifu Olanrewaju Farinde ${ }^{1}$, Johnson Oludare Ojo ${ }^{1} \&$ Yemi Ogunsiji ${ }^{1}$ \\ ${ }^{1}$ Department of English, Adeyemi College of Education, Nigeria \\ Correspondence: Raifu Olanrewaju Farinde, Department of English, Adeyemi College of Education, P.M.B 520, \\ Ondo, Ondo State, Nigeria. E-mail: mikh_fad75@yahoo.com
}

$\begin{array}{ll}\text { Received: February 3, } 2015 & \text { Accepted: March 2, 2015 Online Published: May 30, } 2015 \\ \text { doi:10.5539/ijel.v5n3p88 } & \text { URL: http://dx.doi.org/10.5539/ijel.v5n3p88 }\end{array}$

\begin{abstract}
The English clause is the next higher unit after the group but lower than the sentence in the English grammatical rankscale. It is, most often, central to the analysis of sentence as it accounts for the internal constituents. Therefore, the mastery of the occurrence of the clause in a sentence (structurally or functionally) usually opens up such a sentence. This paper examines the functional values of the English clause with a view to establishing its importance in grammatical description and analysis. It finds out that the clause adds a lot of values to the English sentence. These include its centrality to grammatical rankshift, embedment, configuration of sentences to mention a few. It further establishes the fact that since the sentences is the largest unit of grammatical analysis and the upper limit of structural statement at the grammatical level, the English clause becomes a vital tool in the realization of these analyses.
\end{abstract}

Keywords: unit, clause, sentence, values, analysis

\section{Introduction}

In the traditional sense, the sentence (or potentially complete utterance) has been taken as the largest structure within which a full grammatical analysis is possible (See Quirk \& Greenbaum, 1973, p. 21). This becomes relevant as grammar is concerned with the description and analysis of structures that may be abstracted from stretches of utterance and the inter-relations of the grammar or the language to which the sentence belongs.

These inter-relations among grammatical elements are usually compacted under grammatical rules. The sentence can therefore, be seen as the largest unit of grammatical analysis and the upper limit of structural statement at the grammatical level.

At the grammatical level, the sentence can be seen as a sequence of words which do not form a part of any greater grammatical structure comprising a single clause and usually beginning with a subject followed by a predicator. At the semantic/contextual level, the sentence is described as a group of words which is meaningful. If this is so, it follows therefore that a potentially complete stretch of utterance will be, as a whole utterance, meaningful within the situation in which it is uttered. As a whole, it can be functionally related to the relevant components of the situation, and its meaning explained by reference to a context of situation abstracted from the total extra-linguistic environment for this purpose.

This may also be true of some or all of its constituent parts, (which are, on their own, complete utterances) they need not have independently unstatable semantic functions or meanings; and the meaning of a word or group of words forming part of a larger sentence is not necessarily the same thing as the meaning of that same word or group when constituting a sentence that is complete in its own right. After an exhaustive discussion of the sentence unit with all its constituent parts, this paper examines those values the English clause adds to the sentence in grammatical analysis as a vital constituent part of a sentence.

\section{Theoretical Perspectives}

This study is predicated on the Systemic Functional Grammar (SFG) model. The evolution of this grammatical model is credited to M.A.K Halliday. He was a leading figure of a group (regarded as followers of J.R. Firth) that attempted to do what Firth shunned which was to set up a tightly integrated theory" (See Bolinger, 1986, p. 115). Halliday (1961, 1966d, 1981a, 1985b, 1994) and others inspired by him (See Muir, 1992; Butler, 1983; Morley, 1985; Eggins, 1994; Bloor \& Bloor, 1995; Osisanwo, 1996, 1998; Martin et al., 1997; Thompson, 1997; Ojo, 2011) moved the model away from the 'scale and category' that it was initially predicated on to the 
'systemic functional. The term 'systemic' comes from the chief structural assumption of the theory that language consists of a network of systems. The model looks at language as a whole system of choices existing in complex structural relations. By this, it means a system in which the choice of one thing dictates the choice of another. In the model, the notion of 'constituency' is vital to the analysis of grammatical structures. Eggins (1994, p. 37) posits that "constituency simply means that things are made up of or built out of other things". It therefore, refers to a part/whole relationship between elements of some whole. In essence constituency explains how the parts relate to each other in constituting the whole. A grammatical analysis treats linguistic items not as expressions but as forms which according to Halliday $(1994$, p. 17) is the explanation of language not as sound or as writing but as wording. When we take into account wordings of more than minimal length and complexity, there is the need for constituency analysis since some more structures are involved. This could be done through the use of constituency bracketing and functional labelling/tree diagramming:

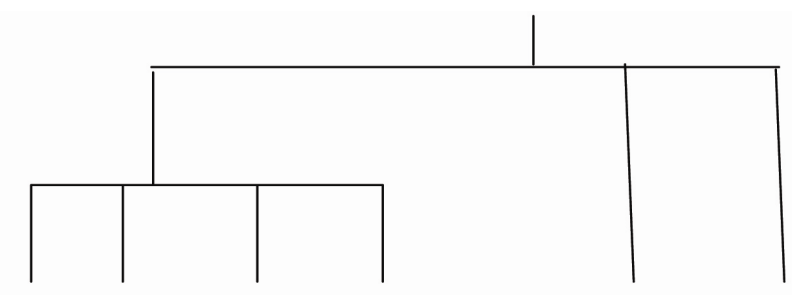

1(a) The two boys with two balls are here

(Minimal bracketing/Ranked Constituents Analysis)

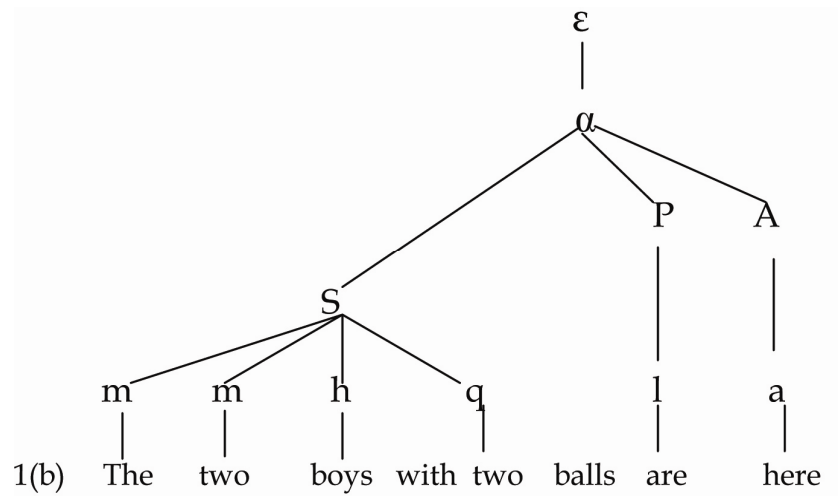

(Functional Labelling/Tree Diagramming)

The present study would adopt Functional Labelling/Tree Diagramming in its description of grammatical structures. The purpose of this is to provide a means of interpreting grammatical structures in such a way as to relate any such instances to the system of the language as a whole. It is our belief that by labelling grammatical functions, we can show what part each component is playing in the overall structure.

\section{The English Clause}

In the Systemic Functional Grammar, the clause is seen on the rankscale as the structural unit next above the rank of the group but next below that of a sentence (See Muir, 1972; Barry, 1975, 1977; Young, 1980 etc). The clause structure is made up of such elements as Subject, Predicator, Complement and Adjunct (SPCA). Consider:

$$
\begin{array}{llll}
\mathrm{S} & \mathrm{P} & \mathrm{C}^{\mathrm{E}} \quad \mathrm{A}
\end{array}
$$

2. Sola/eats/rice/regularly

$$
\begin{array}{lllll}
\mathrm{A} & \mathrm{S} & \mathrm{P} & \mathrm{C}^{\mathrm{E}} \quad \mathrm{A}
\end{array}
$$

3. In fact/ Nigeria / lost/ the match/ to Guinea 
It should be stressed that of all the elements above, only the Predicator is a compulsory element while the others are optional elements:

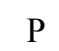

4. Go!

$\mathrm{S} \quad \mathrm{P}$

5. You / should go

$$
\text { S P A }
$$

6. You/ should go/ home.

The clause could be alpha $(\alpha)$ or beta $(\beta)$

The alpha clause is one that can stand on its own while the beta clause cannot as it depends on the alpha clause. Consider:

$\alpha$

7. He left the class // because he was hungry

$\beta \quad \alpha$

8. After the match had ended // the spectators rioted

The beta clause, because of its dependent/subordinate nature, often poses problems. Structurally it can be divided into the finite and non-finite:

$$
\mathrm{S} \quad \mathrm{P} \quad \mathrm{C}^{\mathrm{I}}
$$

9. The man who came here yesterday / is / my brother. (finite)

$$
\text { S P } \quad \mathrm{C}^{\mathrm{I}}
$$

10. The girls playing over there / are/ friends (non finite)

Halliday and Matthiessen (2013) stress that a finite clause is, in principle, independent; it becomes independent only if introduced by a binding (hypotatic) conjunction. If it is joined in a clause complex, its natural status is paratactic. In this case, its logical-semantic relationship to its neighbour is typically shown by a linking paratactic conjuction:

$$
\alpha
$$

$$
\alpha
$$

11. Nobody really thought (about it) (and) it was that bad

$$
\alpha \quad \beta
$$

12. Nobody really thought (that) it was that bad

On the other hand, the non-finite clause is by its nature dependent simply by virtue of being non-finite. It typically occurs therefore, without the other explicit marker of its dependent status. Hence, when a non-finite clause occurs, without a conjunction, there is no doubt about its hypotactic relation in a clause complex; but there may be no indication of its logical-semantic function:

13. Extending the frontiers of knowledge has become imperative.

14. The government has decided to provide basic amenities. 
Eastwood (1994, p. 320) also points out that a finite clause has a main verb:

15. He regrets now that he jumped.

From the sentence above, he identifies 'He regrets now' as the main clause while 'that he jumped' as the subordinate clause. According to him, a non-finite clause has an infinitive, a gerund and (most times) without a subject.

16. To tell you the truth, I was terrified.

17. He regrets now, having jumped.

The position of Eastwood (1994, p. 320) also corroborates the submission of Halliday and Matthiessen on the status of the finite and non-finite clauses.

Eastwood (1994, p. 318) has also identified sentences with more than one clause:

18. The man went up to the $86^{\text {th }}$ floor and he jumped.

The two main clauses linked together by a coordinating conjunction (and in this case, a compound sentence) are called coordinate clauses. There are also instances whereby a main clause and subordinate clause are joined together:

$\alpha$

$\beta$

\section{The man jumped down because he was afraid}

This is an example of a complex sentence. Other sentence patterns with their clausal configurations which include:

1) Compound complex: two main clauses + at least a subordinate clause.

2) Multiple: more than two main clauses.

3) Multiple-complex: more than two main clauses + at least a subordinate clause.

It should be stressed that these clauses are joined together by both the coordinating and subordinating conjunctions.

Functionally, the beta clause can be divided into the nominal, relative and adverbial:

$$
\mathrm{S} \quad \mathrm{P} \quad \mathrm{C}^{\mathrm{I}}
$$

11. What the man said is unclear

Nominal clause

$\begin{array}{lll}\mathrm{S} & \mathrm{P} & \mathrm{C}^{\mathrm{E}}\end{array}$

12. I / own/ the car parked over there

Relative clause
$\beta$
$\alpha$
$\begin{array}{lllllll}A & \mathrm{~S} & \mathrm{P} & \mathrm{S} & \mathrm{P} & \mathrm{A}\end{array}$

13. When I return// we shall go home

Adverbial clause

From this SFG description of the English clause, it is clear that because of its dependent nature, the beta clause impacts so much on the sentence (alpha clause) and the functional values it brings on the sentence in grammatical analysis shall be highlighted presently.

\section{The Functional Values of the English (Beta) Clause on the Sentence in Grammatical Analysis}

One of the functional values is concerned with rankshift in grammatical analysis. Ojo (2011, p. 156) states that the notion 'rankshift' can be defined as a situation whereby a unit that is higher in rank/status occurs in a position under another unit that is lower or equal in rank to it. When this occurs, such a unit can be said to have shifted its rank. The implication of this is that when a beta clause occurs in a sentence, rankshift would determine the status it takes: 


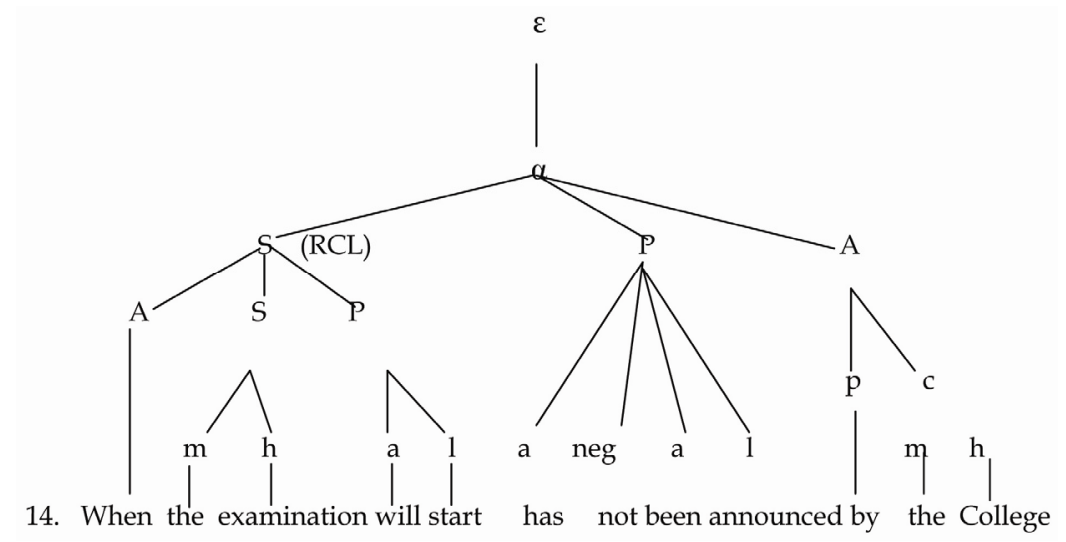

Manifestation (Beta) Clause rankshifted to operate as Subject

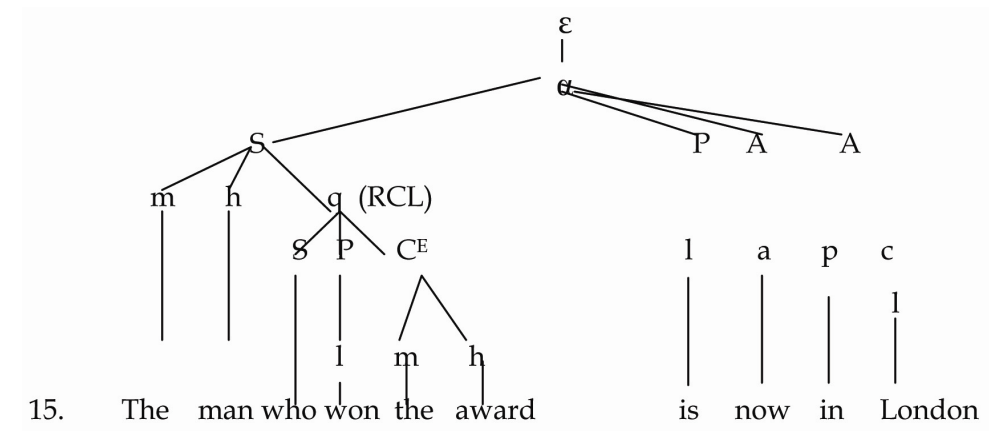

Manifestation Beta Clause ranshifted to operate at qualified (q) in a Nominal Group

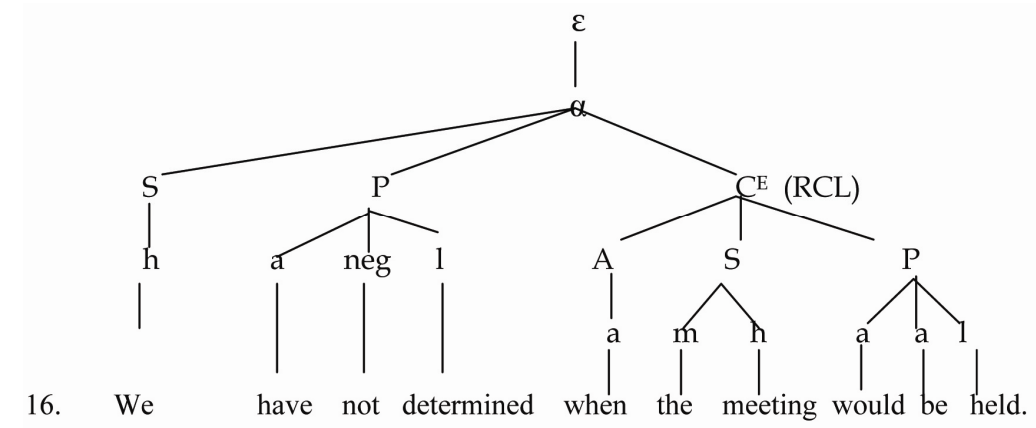

Manifestation (Beta) Clause rankshifted to operate at the Complement (C) position.

A close look at the above analysis, would show that through the application of the rankshift phenomenon, we are able to account for the status and functional value of each of the clauses in the sentence containing it.

Another functional value the (beta) clause has added to the sentence in grammatical analysis is embedment. This refers to a situation in which the clause becomes a tool in containing some information already fixed in the sentence (which can be removed without affecting the sentence) to avoid generating more sentences. Consider:

17. These decisions (that are capable of disintegrating the country) should be expunged from our constitution.

18. We cannot fold our arms (when a great injustice is being perpetrated) and see things degenerate.

19. The new policy of fuel subsidy removal (although already being opposed by the vast majority of the citizens) may eventually sail through if care is not taken.

Most of the clauses embedded in the sentences above string the sentences together instead of generating other sentences to express the information contained in the clauses.

Configuration is also one functional value of the (beta) clause in grammatical analysis. The clause sets out the configuration of a sentence into the simple, complex compound, compound- complex, multiple and multiplecomplex: 
$\beta$

$\alpha$

$\alpha$

20. When the lectures had ended // the student left the class // and // went home.

Summary: 2 alpha clauses $+\mathrm{I}$ beta clause $=$ compound - complex sentence.

$\alpha$

$\beta$

$\beta$

21. All the matches were played outside// because the stadium had gone bad // and // needed repairs

Summary: 2 beta clauses +1 alpha clause $=$ complex sentence

$\alpha$

$\alpha$

$\alpha$

$\beta$

22. He enrolled for the examination// studied very hard// and // passed in flying colours// because he had a focus

Summary 3 alpha clauses +1 beta clause $=$ multiple complex

Configuration deals with the inner constituents of a sentence and in this regard, the clause plays a vital role.

It would be noted that at the surface grammar level, the beta clause plays very prominent roles in the discussion of the functional values it adds to the sentence in grammatical analysis. At the deep grammar level, however, emphasis would be on the alpha/independent clause as systems here act on such clauses. Earlier on, we had identified the SPCA structure of the English clause. Each of these components are accounted for by systems at the deep grammar level.

For instance the mood system accounts for the subject element within the clause structure. It is concerned with the position of a subject in the clauses as well as its presence or absence. Therefore, it accounts for the structures of clauses in the following ways.

23. The man ate the food

(indicative, declarative)

24. What caused the pandemonian?

(indicative, interrogative, with subject question).

25. Stay where you are.

(imperative, jussive, exclusive, without vocative emphasis).

26. Let her face her studies squarely.

(imperative, non-jussive, optative)

It is noted that while 9n (23) and (24) the element subject is visible (indicative) in (25) and (26) the element subject is omitted (imperative).

27. The class is dirty.

(intensive)

28. The teacher caned three pupils.

(extensive, effective, operative, goal realized).

29. The Officer marched the boy scouts.

(extensive, descriptive, operative).

It is observed that while (27) takes a complement intensive, (28) and (29) select complement extensive elements. Also while (28) is an effective clause because the complement element actually, performs the action of marching and not the subject (The officer).

The Theme system accounts for each of the SPCA elements in terms of their places of occurrence within the clause structure. The initial position in a clause is usually occupied by the subject (which is 'unmarked') but when this position is occupied by any of the Predicator, Complement or Adjunct, it is said to be 'marked'. A typical analysis of thematic structure of the English clause would yield something like this:

30. The whole community the epidemic attacked

(marked, C-theme) 
31. Sweep the floor Olu!

(marked P-theme)

32. She works where?

(interrogative, marked INH non-initial)

33. The girl believes in hardwork

(unmarked theme)

Here like (30), (31) and (32) are marked for theme, (33) is unmarked because it has the typical initial position occupied by a subject element.

The whole essence of the deep grammar borders on semantics (meaning). All the systemic choices/options that are available for selection at the deep grammar are sieved so that the semantic chemistry of elements at the surface grammar is not, in any way affected.

\section{Conclusion}

The present study has established the fact that the English clause, by its very nature, impacts so much on the sentence in grammatical analysis. The functional values it adds to the sentence in grammatical analysis have helped to project the sentence in such a way that accessibility problems that are usually associated with the learners and users particularly in a second language situation are avoided.

\section{References}

Berry, M. (1975). Introduction to Systemic Linguistics I: Structure and Systems. New York: St. Martins.

Berry, M. (1979). Introduction to Systemic Linguistics 2: Levels and Links. New York: St. Martins.

Bloor, T., \& Bloor, M. (1995). The Functional Analysis of English: A Hallidayah Approach. New York: Oxford University Press.

Butler, C. S. (1983). Systemic Linguistics: Theory and Applications. London: Batsford.

Eastwood, J. (1994). Oxford Guide to English Grammar. Oxford: Oxford University Press.

Firth, J. R. (1951). Papers in Linguistics (1934-1951). London: O. U. P.

Halliday, M. A. K. (1961). Categories of the Theory Grammar. Word, 17(3).

Halliday, M. A. K. (1966d). The Verbal Group: A Specimen of Manual of Analysis. Nuffield Programme in Linguistics and English Teaching Working Paper VI.

Halliday, M. A. K. (1985a). An Introduction to Functional Grammar (1st ed.). London: Edward Arnold.

Halliday, M. A. K. (1985b). Spoken and Written Language. Geelong Vic: Deakin University Press.

Halliday, M. A. K. (1994). An Introduction to Functional Grammar (2nd ed.). London: Edward Arnold.

Halliday, M. A. K., \& Matthiessen, M. I. M. (2013). Halliday's Introduction to Functional Grammar (4th ed.). London: Routledge.

Martin, J. R. et al. (1997). Working with Functional Grammar. London: Arnold.

Morley, G. D. (1985). An Introduction to Systemic Grammar. London, Macmillan.

Muir, J. (1972). A Modern Approach to English Grammar: An Introduction to Systemic Grammar. London: IBT Batsford Ltd.

Ojo, J. O. (2011). A Contemporary Functional Grammar of English. Ago-Iwoye: Olabisi Onabanjo University Press.

Osisanwo, W. (1996). Systemic Functional Grammar as a Model of Grammatical Description: An Evaluation. In V. E. A. Akorede (Ed.), Journal of Arts and Social Science (pp. 1-19). Ondo: Ife-Oluwa Press.

Osisanwo, W. (1999). An Introduction Analytical Grammar of English for Undergraduates Book 7 (A Systemic Functional Approach). Lagos: Femolous Fetop Publishers.

Quirk, R., \& Greenbaum, S. (1973). A University Grammar of English. London: Longman.

Thompson, G. (1997). Introducing Functional Grammar. New York: Oxford University Press Inc.

Young, D. J. (1980). The Structure of English Clauses. London: Hutchinson. 


\section{Copyrights}

Copyright for this article is retained by the author(s), with first publication rights granted to the journal.

This is an open-access article distributed under the terms and conditions of the Creative Commons Attribution license (http://creativecommons.org/licenses/by/3.0/). 